\title{
LA CRISIS EN EUROPA DEL ESTE Y LA IZQUIERDA EN AMÉRICA LATINA*
}

$\mathrm{E}$ derrumbe de los regímenes del "socialismo realmente existente" en Europa del Este es, en lo inmediato, casi una catástrofe para la mayoría de las gentes de "izquierda" de todo el mundo, no solamente para las de América Latina. La desmoralización y / o la perplejidad empujan a muchos a la desocupación política; a no pocos a pasarse con armas y bagajes al campo contrario o, lo que es casi lo mismo, a un pragmatismo sin atenuantes. Algunos procuran aún guarecerse detrás de esa suerte de vulgata marxista que el dominio burocrático fue secretando, desde mediados de los años veinte, como su "ortodoxia".

Sin embargo, para el mediano y, sobre todo, para el largo plazo, la crisis de tales regímenes inicia una liberación de la pesada hipoteca in-

* Publicado en: Quijano, Aníbal 1995 El fujimorismo Y el Perú (Lima: SEDES) pp. 45-48. Primera edición en: Cultura Libre, Suplemento de Pagina Libre (Lima), 29 de agosto de 1990. telectual y política que el estalinismo colocó sobre toda la izquierda, afectando en cierta forma inclusive a las corrientes y grupos antiestalinianos, pues toda la problemática del socialismo fue implicada. Los escombros del mundo posestaliniano hacen posible la desmitificación del debate socialista. Hacen patente la necesidad de volver a partir en ese debate $\mathrm{y}$, al mismo tiempo, deslindan un nuevo punto de partida. De esa manera será posible reconstituir más pronto las bases de una crítica revolucionaria del poder, y de otro proyecto de sociedad alternativa.

Una de las cuestiones centrales que tienen que ser decididas en el nuevo punto de partida es el dominio del eurocentrismo en la manera de conocer la realidad social, y en particular en el empleo y en el desarrollo del legado intelectual de los principales teóricos del socialismo europeo, Marx en primer lugar. Para el debate y para la práctica del socialismo en América Latina eso es, sin duda, una condición 
imprescindible. El eurocentrismo consiste en una perspectiva según la cual todas las experiencias históricas son "leídas" según la experiencia de Europa; las sociedades en América Latina o en el resto del "Tercer Mundo" serían inteligibles solamente como si fueran Europa, no a partir de las especificaciones históricas de tales sociedades. El predominio de semejante perspectiva en el pensamiento revolucionario fue una de las marcas del poder estaliniano, y no cabe duda de que impidió el conocimiento efectivo de nuestra realidad y, algunas veces, llevó a la sustitución de ésta por esquemas casi puramente ideológicos. El término de la larga prisión estaliniana sobre el pensamiento socialista podrá llevar también a la cancelación del eurocentrismo, y no sólo en América Latina. Los propios europeos, y no menos urgentemente, deben ser ayudados a defenderse del eurocentrismo.

Para esas tareas hay en América Latina, bajo las cenizas del predominio del "socialismo realmente existente", un rico y complejo legado intelectual y político revolucionario, que es importante rescatar. Por ejemplo, el debate sobre la cuestión nacional fue en América Latina, hasta fines de los años treinta de este siglo, no menos original y rico que en Europa de ese mismo período: baste aquí mencionar a Martí, Mariátegui, Haya. Después de todo, fue en América Latina que comienza la historia de ese debate, desde fines del Siglo XVIII. La experiencia de formación de movimientos y partidos revolucionarios, desde las bases mismas de los grupos explotados y dominados $\mathrm{y}$, por eso, de modo profundamente democrático y antiburocrático, fue muy extendida antes de 1930. Los casos del Partido Socialista de Puerto Rico, a pesar de la derrota final de sus tendencias radicales bajo el peso del colonialismo yanqui y del gomperismo sindical; del Partido Revolucionario Socialista de Colombia, en los mismos años, cuyas discusiones registran uno de los más intensos momentos del desarrollo de la democracia revolucionaria en el seno de los grupos de trabajadores, antes de ser víctimas de la masacre de 1927; del movimiento obrero chileno, que ya hacia 1912 defendía el socialismo. De otro lado, la rica historia de los movimientos anarquista y anarco-sindicalista en virtualmente todos estos países, estuvo muy lejos de ser, simplemente, una prolongación de la experiencia europea, si se recuerda, por ejemplo, a González Prada y sus propuestas sobre lo indio y la cuestión nacional. La experiencia de los movimientos populares de orientación democrático-nacionalista radical, el primero de los cuales, a pesar de la derrota 
de sus tendencias más radicales, terminó con la destrucción del poder oligárquico en México, no consistió solamente en un caso particular de una "revolución democrático-burguesa" a la europea, y su debate latinoamericano tampoco ha seguido únicamente la canónica del estalinismo. O, en fin, las experiencias revolucionarias posteriores, desde la década de los veinte, pasando por la revolución boliviana de 1952, por la Asamblea Popular del 71-72, en ese mismo país, hasta la derrota de los procesos de los años setenta, serían ininteligibles desde una perspectiva eurocentrista. Ahora es el tiempo de abandonarla y dejar la mirada colonial, definitivamente.

Acerca de eso, es pertinente recordar que fue la Primera Conferencia Comunista de América Latina reunida en Buenos Aires, en junio de 1929, por el Buró Latinoamericano de la III Internacional, bajo su estrecho control la primera gran ocasión del enfrentamiento entre el pensamiento revolucionario latinoamericano, con sus específicas perspectivas sobre la realidad social de estos países y con sus propios proyectos revolucionarios, y, de otro lado, la "ortodoxia" estaliniana. Del lado latinoamericano estuvieron, sobre todo, la delegación colombiana con Maecha a la cabeza, y la peruana que sostenía las tesis de José Carlos Mariáte- gui. Ambas fueron virtualmente condenadas por la dirección estaliniana. No fue a ésta, sin embargo, a la que 60 años de historia posterior ha confirmado.

En realidad el debate latinoamericano ha retomado cauces propios ya desde fines de la Segunda Guerra Mundial, especialmente en las décadas de los sesenta y setenta, y a pesar del cambio posterior de la correlación de fuerzas, por las derrotas de virtualmente todos los movimientos y regímenes de carácter popular de esa etapa, y de la extendida influencia de las versiones más reaccionarias del liberalismo, sus corrientes no se han extinguido. Es, en gran medida, sobre esas bases que está comenzando, de nuevo, el reconocimiento de la realidad social latinoamericana, en el nuevo contexto mundial.

En efecto, después de casi dos décadas de ininterrumpida crisis del capitalismo en estos países, la estructura de poder, en cada una de sus áreas, es ampliamente diferente. Las relaciones sociales que se ordenan en torno del dominio del capital, son ahora muy cambiadas. La actual crisis política de todos los países latinoamericanos muestra, entre otras cosas, que se ha producido una distancia muy grande entre la estructura, sus instituciones sociales y el Estado, y que hay una crisis abierta de repre- 
sentación política. La situación de la mayoría de los partidos de izquierda hace parte de esa problemática. Si algo llamable "izquierda" (no hay más remedio que usar el término con todas las salvedades de un entrecomillado, dada la situación actual) puede ser reconstituida en el periodo que comienza, no puede partir sino de esa tarea, la de un reconocimiento de nuestra realidad, dentro del nuevo contexto mundial. Es decir, de la reconstitución de una crítica revolucionaria del poder existente, de los supuestos y categorías que se produzcan en ese trabajo, que permitan producir o ir produciendo una nueva utopía, como proyecto de un nuevo sentido histórico de la existencia social en estas tierras. Lo que no asuma esa larga y delicada tarea, que es parte de la lucha cotidiana en contra de la explotación y de la dominación difícilmente sería distinto de la "izquierda" que hoy sigue tratando de cogobernar el orden existente.

De otro lado, la propaganda capitalista insiste en que es el socialismo lo que llega al final de su historia, en la crisis de los regímenes de Europa del Este. Sin embargo, la cuestión no es tan simple. De hecho, la mayoría de las posiciones que están en debate dentro de la izquierda, no admiten el carácter socialista de aquellas sociedades: Capitalismo de Estado
(Bettelheim); Colectivismo Burocrático (Mellotti); nuevo tipo de sociedad de dominación (Bahro); muchos estudiosos en la propia $\mathrm{Ru}-$ sia sostienen hoy el carácter de clase del poder existente (Davies), como Djilas antes (La Nueva Clase); eso se acerca a la hipótesis de la posible mutación de la "deformación burocrática”, si llegara a durar más de lo previsto, en un poder de clase (Trotsky); el propio Gorbachov emplea la fórmula de "sistema de comando administrativo" para el dominio de un partido único en el Estado. Y esta lista no es, en modo alguno, exhaustiva. Se trata, como no podría ser de otro modo, de una problemática vasta y compleja, que excluye un debate simplista o mal intencionado.

En el periodo que termina, el debate fue entrampado en un falso problema: si propiedad privada o propiedad estatal; si empresa privada o empresa estatal. Pero 70 años después no hay modo de no ver que se trata, en definitiva, de las dos caras de lo mismo. Fue una economía de control estatal que se llamó socialista, y es ella la que se derrumba. El capitalismo privado pretende cantar victoria. Inclusive proclama, Fukuyama mediante, nada menos que el fin de la Historia y el comienzo del eterno reinado del capital y del liberalismo.

La historia, sin embargo, apenas comienza 
en realidad. El socialismo como proyecto alternativo al capitalismo no se originó en el sueño de un nuevo poder estatal, cualquiera que fuese su carácter. Fue el proyecto de la democracia directa: elección y control directo de la autoridad; debate y decisión como su modo normal de ejercicio; reciprocidad como relación social básica, piso de la solidaridad social: espacio creciente del libre desarrollo individual. Única fuente y cauce de un continuado proceso de erradicación de la explotación y de la dominación. Esa fue también la inferencia de Marx después de la Comuna de París. Ese proyecto no es lo que ahora colapsa con el "socialismo realmente existente".

Se sabe que ese debate ya está activo entre los explotados y dominados, inclusive en $\mathrm{Ru}-$ sia y otros países que se liberan de la represión burocrática, como lo está en varios otros lugares, y ciertamente en América Latina. Entre los nuevos movimientos populares de esta región, así como en otras partes del "Tercer Mundo", los más importantes vienen de esas nuevas fuentes y se orientan en esa dirección. Las formas específicas que sus instituciones cobren, así como las formas de su enfrentamiento con el poder vigente, difícilmente serían idénticas en un mundo heterogéneo. En América Latina, la reconstitución de institu- ciones de tipo comunitario en las ciudades empobrecidas, o la revitalización y cambio de las comunidades rurales de larga y continuada historia, puede ser mirada como parte de ese proceso. $\mathrm{Y}$ estamos apenas en los umbrales del nuevo período histórico.

Los regímenes formados en los procesos revolucionarios previos, y que lograron sostenerse hasta hoy, como en el caso de Cuba, difícilmente podrían continuar sosteniéndose con todas sus actuales características aisladas. "Ya no hay campo socialista", ha dicho el propio Fidel Castro. Pero no es cierto que la única opción alternativa sea la plena restauración del capitalismo liberal. Por el contrario, se trata allí, como en todas partes donde fuera posible, de una profunda transformación en la dirección de una democracia directa como la expresión precisa de la democracia socialista, alternativa a la democracia liberal. Pero son las propias masas las que allí, como en los demás lugares, tienen la palabra.

Mientras parece que se hunde el "socialismo realmente existente", el poder del capital se extiende a escala planetaria. La explotación y la dominación no se han terminado, en consecuencia. Y esa es, exactamente, la cuestión central del socialismo: la lucha contra la explotación y contra la dominación, en todo tiempo 
y en todo lugar donde existan, bajo cualquier forma. No solamente contra los explotadores y dominadores específicos del capitalismo. En ese sentido, la experiencia con el "socialismo realmente existente", así como las tendencias actuales del poder capitalista y de los nuevos movimientos sociales y políticos, conducen, sin duda, a una fundamental redefinición de la idea misma de una revolución socialista. Eso parte de liberarla de la falaz disyuntiva en que el estalinismo y el liberalismo la entramparon hasta hoy, entre el capitalismo privado y la estatización de la economía y de la sociedad. Las luchas contra la explotación y la dominación se orientarán, en adelante, hacia la democracia directa, como la más eficaz manera de asegurar y desarrollar la solidaridad social, la libertad individual y la democracia cotidiana de la sociedad. Esa es, después de todo, la más larga y continuada utopía de América Latina.

Lima, julio de 1990. 